\title{
Inguinal Hernia Mesh Repairs: Plug and Patch Versus Lichtenstein Mesh Repair Technique: A Teaching Hospital Based Study
}

\author{
Dharam Vir Singh ${ }^{1}$ \\ ${ }^{1}$ Assistant Professor, Department of Surgery, World College of Medical Sciences Research and Hospital, Gurawar, Jhajjar-124103.
}

\section{Abstract}

Background: Hernia repair is one of the most commonly performed general surgical procedures worldwide. Subjects and Methods: 50 subjects, of type 1, 2 and 3 inguinal hernias, according to Gilbert's classification of groin hernias, admitted in the surgical unit in the form of randomized controlled trial of plug and patch versus lichtenstein mesh repair technique in two groups of randomly selected 25 cases of inguinal hernias each. Results: Out of total fifty (50) patients, 35 (70\%) patients were having right indirect inguinal hernia, 15 (30\%) patients were having left indirect inguinal hernias and none was having bilateral inguinal hernias. From the above data it is clearly shown that there is much higher incidence of right sided indirect inguinal hernias as compared to the left sided indirect inguinal hernias. Conclusion: Lichtenstein and plug and patch inguinal hernia repair, are equally good in terms of negligible intra-operative, post-operative complications and overall outcome with good patient compliance and satisfaction.

Keywords: Inguinal Hernia Complications, Plug \& Patch and Lichtenstein Mesh Repair Technique.

Corresponding Author: Dr. Dharam Vir Singh, Assistant Professor, Department of Surgery, World College of Medical Sciences Research and Hospital, Gurawar, Jhajjar-124103

Received: July 2019

Accepted: July 2019

\section{Introduction}

Inguinal hernia repair remains one of the most commonly performed operations worldwide. A hernia is defined as an abnormal protrusion of a viscus or a part of it, through the wall that contains it but without a breach in the body surface. By far the commonest variety of hernia is the protrusion of abdominal wall. Inguinal hernia most probably has been a disease ever since mankind existed. ${ }^{[1]}$ In humans, the upright posture causes the gravitational stress to pass down to the lower abdominal wall. Furthermore, the inguinal canal is directed downwards, and the intraabdominal contents pressing on its internal opening tends to dilate it and cause the loops of bowel to enter the canal. ${ }^{[2]}$ Operation for the inguinal hernia is one of the most common procedure that a general surgeon undertakes and various surgeons have given their valuable contribution to different techniques of inguinal hernia repair for better outcome in relation to various complications like groin pain, infection, testicular atrophy and recurrence etc. related to older techniques. The history of open surgery for groin hernia has gone through many stages of development from ancient era to the era of tensionless repair. Through these periods of development, five principles of the modern hernia repair were developed, which includes: ${ }^{[3]}$ Antiseptic/aseptic hernia repair; High ligation of the sac, Tightening of the internal ring, Reconstruction of the posterior wall ofinguinal canal and Tensionless repair.
Although the first ever inguinal floor reconstruction was performed by Bassini in 1881, there have been plenty of modifications given by various surgeons for inguinal hernia repairs, each claiming his repair more anatomical, more accurate with much less tension. However, whatever modification one may make, some tension on the suture line for these herniorrhaphies was inevitable. So the rate of recurrence was still high, even after newer techniques of tissue based non-mesh hernia repair. Still newer concepts, modern materials and recent experimental evidences invite re-evaluation of established surgical tenets. In past, hernia repair done with undue tension using patient's own tissue suggested by Kirschner et al, lead to failure in unacceptably high percentage of the patients and the failure rate was even more higher following the repair of recurrent hernias. ${ }^{[4]}$ Not only does the inherited weakness of the tissue lead to failure, the ischemic necrosis of the tissues by the sutures holding the anatomically different structures under tension was the major culprit. The problem is that most inguinal hernia repairs are based upon the Bassini's principle of suturing the conjoint tendon to the inguinal ligament but the ease, with which these can be opposed, depends upon individual anatomy of these structures. The gap between these two may be less in some and more in others. In this situation, the two structures can be approximated with great tension by surgeon. Some surgeons tried to compromise this by using "relaxing" incision to lessen the tension, but the contribution of this manoeuvre in reducing the incidence of recurrence is still questionable. ${ }^{[3]}$ Further, when muscle 
aponeurotic tissues are present, sutures will hold to a great degree but the fleshy musculature will cut through more easily, especially if sutures are placed under tension. Successful hernia repair must include achievement of an effective repair with the lowest possible recurrence, minimal operative and post-operative discomfort with a rapid return to normal activity. Success of groin hernia repair depends largely on the surgeons, understanding of the functional anatomy and pathophysiology of the abdominal wall and groin, as well as the knowledge that how to use the currently available techniques and materials most effectively. Since Bassini et al described his primary inguinal hernia repair in 1890, many advancements and modifications of groin herniorrhaphy and hernioplasty have been described..$^{[5,6,9-14]}$ The most important advance in hernia surgery has been the development of tension free repairs. By now the notion of minimizing tension in a groin hernia repair, to reduce the risk of recurrence, was becoming more popular. This eventually led to mesh repair techniques. The difficulty was finding the appropriate material. Metal sheets were first introduced, but they were fraught with complications. Credit for the successful introduction of mesh should be attributed to Usher. He initially used polyethylene and later substituted it with polypropylene mesh in the 1950's. Stoppa (1980's) also made a significant contributions in this area of surgery by giving "giant prosthetic repair of the visceral sac". Mesh plugs were first introduced by Lichtenstein and Shore, ${ }^{[14]}$ for femoral and recurrent hernias in the 1970's. In a landmark study, he reported 0\% recurrence and $0 \%$ infection in 1,000 consecutive patients who underwent tension-free repair with mesh. ${ }^{[15]}$ Gilbert et al described a sutureless mesh-plug and patch repair for indirect hernias in the 1980s, based on input from Usher ${ }^{[16]}$ Rutkow et al followed this with a description of a mesh plug and patch repair for all varieties of inguinal hernias in the early 1990 's. ${ }^{[16-18]}$ Since then, Rutkow et al have reported their repair results with a premade manufactured plug and patch. ${ }^{[19]}$ Since the 1970 's, the use of polypropylene meshes have become increasingly popular. Multiple forms of hernia meshes have been manufactured and multiple approaches have been described. The most popular open mesh repairs today include a lichtenstein patch, Plug and patch and prolene hernia system. All these modified tensionless techniques of hernioplasties are preferred treatment modalities in most of the institutes in these days. The reported advantages of using these mesh repairs include low recurrence rates, less postoperative pain, and quicker return to regular activities. The advent of laparoscopy has also resulted in the introduction of laparoscopic mesh repairs for still better outcome and patient comfort. Tensionless mesh repairs for inguinal hernias have become generally accepted as the solution to reduce tension on a repair during the past two decades to get better results in terms of complications of tissue based inguinal hernia repairs. The purpose of this study was to evaluate an improved and simple technique of mesh repair in inguinal hernia patients in the form of randomized controlled trial of plug and patch versus Lichtenstein mesh repair technique.

\section{Subjects and Methods}

This present study was conducted in the Department of Surgery at World College of Medical Sciences Research and Hospital, Gurawar, Jhajjar. The diagnosis of primary inguinal hernia was made on basis of history and clinical examination. Total of 50 patients, of type 1,2 and 3 inguinal hernias, according to Gilbert's classification of groin hernias, admitted in the surgical unit at World College of Medical Sciences in the form of randomized controlled trial of plug and patch versus lichtenstein mesh repair technique in two groups of randomly selected 25 cases of inguinal hernias each, during the period of eleven months i.e., from March 2017 to January 2018. Cases were allotted to either group by random selection. All patients underwent routine investigations in the form of fasting blood sugar, haemoglobin, bleeding time, clotting time, complete urine examination and an ECG. In case of any co-morbid cardiac or pulmonary condition, a physician was consulted for medical fitness. All patients were operated upon under spinal anesthesia. All patients were given a preoperative prophylactic intravenous single dose of $1.5 \mathrm{gm}$ of cefuroxime sodium. Majority of the patients were discharged within a period of two days, two patients on 3rd day and one on 4th post-operative day.

\section{Statistical Analysis:}

Paired T test for quantitative data and Pearson chisquare test for qualitative data were used to evaluate the $\mathrm{P}$ value. Differences were considered statistically significant, if $\mathrm{P}<$ 0.05. IBM SPSS Statistics for Windows, version 16 software program was used for statistical calculations.

\section{Results}

This present study was conducted in the Department of Surgery at World College of Medical Sciences Research and Hospital, Gurawar, Jhajjar. The diagnosis of primary inguinal hernia was made on basis of history and clinical examination. A total of 50 patients, of type 1,2 and 3 inguinal hernias, according to Gilbert's classification of groin hernias, admitted in the surgical unit. All patients included in this study were male. The youngest patient was 20 years old and the oldest was 70 years old in table- 1 . In this study conducted on two groups and the data collected above reveals that the maximum incidence of hernia i.e. $30 \%$, is found in the 4 th decade of life.

\begin{tabular}{|l|l|l|}
\hline Table 1: Shows the distribution of patients age wise \\
\cline { 2 - 3 } Variables & Number of patients \\
\cline { 2 - 3 } & Plug and patch & Lichtenstein \\
\hline $20-30$ & $5(20 \%)$ & $2(8 \%)$ \\
\hline $31-40$ & $9(36 \%)$ & $7(28 \%)$ \\
\hline $41-50$ & $8(32 \%)$ & $10(40 \%)$ \\
\hline $51-60$ & $2(8 \%)$ & $4(16 \%)$ \\
\hline $60-70$ & $1(4 \%)$ & $2(8 \%)$ \\
\hline$>75$ & $0(0 \%)$ & $0(0 \%)$ \\
\hline Total & $25(100 \%)$ & $25(100 \%)$ \\
\hline
\end{tabular}


Table 2: Shows the type of hernia

\begin{tabular}{|l|l|l|}
\hline \multirow{2}{*}{$\begin{array}{l}\text { Type of } \\
\text { hernia }\end{array}$} & Number of patients \\
\cline { 2 - 3 } & Plug and patch & Lichtenstein \\
\hline Right side & $19(76 \%)$ & $16(64 \%)$ \\
\hline Left side & $06(24 \%)$ & $09(36 \%)$ \\
\hline Bilateral & $0(0 \%)$ & $0(0 \%)$ \\
\hline Total & $25(100 \%)$ & $25(100 \%)$ \\
\hline
\end{tabular}

In this study, out of total fifty (50) patients, $35(70 \%)$ patients were having right indirect inguinal hernia, 15 $(30 \%)$ patients were having left indirect inguinal hernias and none was having bilateral inguinal hernias. From the above data it is clearly shown that there is much higher incidence of right sided indirect inguinal hernias as compared to the left sided indirect inguinal hernias.[20] In this study for plug and patch inguinal hernia repair, time taken to complete the operation was <30minutes in 00 $(00 \%)$ cases, 31-35 minutes in $13(52 \%)$ cases, 36-40 minutes in $10(40 \%)$ cases, $41-45$ minutes in $02(8 \%)$ and 46-50minutes in $01(4 \%)$ case. In the lichtenstein inguinal hernia repair, time taken to complete the operation was $<30$ minutes in $00(00 \%)$ cases, 31-35 minutes in $11(44 \%)$ cases, 36-40 minutes in $8(32 \%)$ cases, $41-45$ minutes in 04 $(16 \%)$ cases, 46-50minutes in $02(8 \%)$ cases. The results of above given comparison data reveals statistically not significant difference was observed ( $p>0.05)$. It is studied that both techniques usually take 30-65 minutes of operative time with minor differences attributed to the time taken to tailor the mesh plug and surgical experience. ${ }^{[21]}$

Table 3: Shows the post-operative hospital stay time of patients

\begin{tabular}{|l|l|l|}
\hline \multirow{2}{*}{$\begin{array}{l}\text { Hospital } \\
\text { stay }\end{array}$} & Number of patients \\
\cline { 2 - 3 } & Plug and patch & Lichtenstein \\
\hline 1 day & $19(76 \%)$ & $13(52 \%)$ \\
\hline 2 days & $04(16 \%)$ & $10(40 \%)$ \\
\hline 3 days & $02(8 \%)$ & $01(4 \%)$ \\
\hline$>3$ days & $0(0 \%)$ & $01(4 \%)$ \\
\hline
\end{tabular}

In this study, as shown in the above table, in lichtenstein repair $13(52 \%)$ patients were discharged on 1stday, 10 (40\%) patients on 2nd day, one (4\%) patient on 3rd and one (4\%) on 4th post-operative day. On the other hand, in plug and patch group of patients, $19(76 \%)$ patients were discharged on 1st day, $04(16 \%)$ patients on 2nd day and two $(8 \%)$ patient on 3rd post-operative day. In this study none of the patient, in any of the study group was discharged on the day of operation. In this study, the results found were statistically not significant $(p>0.05)$, which concludes that there is no difference for post-operative hospital stay in both study groups.

\begin{tabular}{l|l|l|}
\hline \multirow{3}{*}{ Table 4: Shows the post-operative complications in patients } \\
\cline { 2 - 3 } Complication & Number of patients \\
\hline Pain & $01(4 \%)$ & Lichtenstein \\
\hline Retention urine & $01(4 \%)$ & $02(8 \%)$ \\
\hline Wound infection & $01(4 \%)$ & $01(4 \%)$ \\
\hline Scrotal hematoma & $01(4 \%)$ & $01(4 \%)$ \\
\hline Wound seroma & $02(8 \%)$ & $01(4 \%)$ \\
\hline Recurrence & $00(00 \%)$ & $03(12 \%)$ \\
\hline Mesh removal & $00(00 \%)$ & $00(00 \%)$ \\
\hline
\end{tabular}

In the present study, both the study groups were compared in relation to various post-operative complications as mentioned above. Two (8\%) patients in lichtenstein group and one $(4 \%)$ patients in plug and patch group complained of pain on the wound site, which was relieved with analgesics. One patients in each study group developed urine retention, because of associated benign hyperplasia of prostate as a comorbid condition. Both patients were catheterized with K-90 catheter to empty the urinary bladder. Three (12\%) patients in Lichtenstein and two (8\%) patients in plug and patch study group developed wound seroma in post-operative period. All these patients were reassured and seroma resolved spontaneously with time. Wound infection was encountered in one (4\%) patients of lichtenstein and one (4\%) patients of plug and patch hernia repair. It was corrected with antiseptic dressing along with oral antibiotics and anti-inflammatory drugs. Scrotal hematoma was encountered in one $(4 \%)$ patients of Lichtenstein and one (4\%) patients of plug and patch study group. In these groups, patients were managed conservatively and hematomas resolved spontaneously with time. In none of the study group of tension free inguinal hernia repair, recurrence encountered and in both the study groups, none of the patient required mesh removal. There was no significant difference in the post-operative complications in both the groups.

\section{Discussion}

Inguinal hernia operations are still one of the most commonly encountered procedures in the lifetime of a general surgeon. While it is seen frequently, it is generally considered as a simple operation, but its anatomical planes are complicated. ${ }^{[22]}$ Although surgical treatment dates back to considerably old times, modern surgical treatment is recognized to begin with Bassini. ${ }^{[23]}$ In hernia surgery, the best indicator of the success of the operation is the recurrence which is totally based on objective criteria. Hernia repair is one of the most common surgical procedures performed worldwide. Improvements in surgical technique, together with the development of new prosthetic materials and a better understanding of how to use them, have significantly improved outcomes for many patients. These improvements have occurred most notably in centres specializing in hernia surgery, with some institutions reporting failure rates of less than $1 \% .{ }^{[24]}$ In contrast, failure rates for general surgeons, who perform most hernia repairs, remain significantly higher. Success of groin hernia repair is measured primarily by the permanence of the operation, fewest complications, minimal costs, and earliest return to normal activities. This success depends largely on the surgeon's understanding of the anatomy and physiology of the surgical area as well as knowledge of how to use most effectively the currently available techniques and materials. ${ }^{[24]}$ Every type of tension-free repair requires a prosthetic mesh, whether it is done through an open anterior, open posterior or laparoscopic route. The most common prosthetic open repairs done today are the 
Lichtenstein onlaypatchrepair, the plug and patchrepair and prolene hernia system bilayer patchrepair. After introduction of an inert plastic mesh in hernia repair by Usher and colleages, increasing acceptance of this method has been in large measure due to the impressive series of reports by Lichtenstein and colleagues in the past 20 years. ${ }^{[11,25]}$ Lichtenstein completely discarded the muscle tendon type of repair. He promoted the technique of strengthening the weak posterior wall by fashioning a new deep ring with prosthetic mesh placed without any tension, which was further modified to plug and patch technique given by Ruthkow and Robbins.

The use of mesh in hernia repair was given a further significant boost by the pioneer work of Stoppa and colleagues and Rives and associates. ${ }^{[10,26]}$ Gilbert subsequently reported the use of an unsutured mesh support for internal ring. ${ }^{[27]}$ Open mesh repair by Lichtenstein has significantly reduced recurrences as compared with conventional open nonmesh repair. This finding was also supported by several other studies and it has been stated that using a mesh for open repair reduces recurrence rate by $50 \%$ to $75 \%$ when compared with open suture repair. ${ }^{[28]}$ Worldwide, it is estimated that approximately 1 million meshes are implanted per year. The most commonly used mesh material for mesh repairs currently use polypropylene mesh. ${ }^{[29]}$ A study conducted for open "tension-free" Lichtenstein hernia repair of inguinal hernias by Amid PK et al, concluded that repair of primary inguinal hernias under local anaesthesia with the open tension-free technique using polypropylene mesh results in acceptable morbidity and appreciable reductions in postoperative discomfort, duration of hospital stay, recurrence rate and costs. ${ }^{[30]}$ Baracs $\mathrm{J}$ et al had done a retrospective study on Long-term results of open tension-free and tension repair of inguinal hernias. ${ }^{[31]}$ Based on this retrospective study, Lichtenstein repair was superior to non-mesh open inguinal reconstruction in relation to recurrence rates, but chronic pain and recovery time show similar long term results in both groups. Another study conducted by Rutkow IM et al for "tension-free" plug and patch inguinal hernioplasty concluded that as compared with conventional sutured surgical techniques, a plug repair uses less overall dissection and ensures a "tension-free" hernioplasty. ${ }^{[32]}$ They believed that the two factors of no. tissue tension and decreased dissection are the most important reasons for greater patient comfort, rapid rehabilitation, decreased recurrence, and lessened overall complication rates with the mesh hernia plug technique. As compared to above studies of mesh hernioplasties, in our study, minor complications like wound seroma and wound infection were encountered in very few patients who lead to better patient compliance and good rehabilitation. These minor complications like wound infection and seroma were managed successfully with antibiotic/anti-inflammatory drugs and reassurance respectively. Pierides $\mathrm{G}$ et al conducted a prospective randomized clinical trial comparing the prolene hernia system (comparable to plug and patch repair) and Lichtenstein patch technique for inguinal hernia repair in long term which concluded that the two approaches resulted in comparable rates of recurrence and long-term chronic postoperative pain. ${ }^{[33]}$ The Lichtenstein patch caused significantly (more often) long-term sensory dysfunction of the skin in the operated groin. Benizri EI et al done a study on open inguinal herniarepair by plug and patch: the value of fibrin sealant fixation; the results of which confirms the effectiveness of fibrin glue in securing prosthetic meshes and reducing chronic inguinal pain. ${ }^{[34]}$ In another productive prospective randomized controlled trial for tension-free inguinal herniarepair: TEP versus meshplugversusLichtenstein by Bringman $S$ et al concluded that laparoscopic hernioplasty is superior to tension-free open herniorrhaphy in terms of postoperative pain and rehabilitation. ${ }^{[35]}$ A study conducted by Keith $\mathrm{W}$ et al concluded that the plug and patch hernioplasty is associated with less amount of postoperative pain and early return to normal activities and manual labour with a minimal documented early recurrence rate. ${ }^{[36]} \mathrm{Fei} \mathrm{L}$ et al concluded in their study that the plug and patch mesh repair satisfy all the requirements of a feasible, reliable, and effective device for repairing primary inguinal hernia with high patient comfort. ${ }^{[37]}$ Comparative study between Lichtenstein patch hernioplasty versus tailored plug and patch hernioplasty as a treatment of inguinal hernia conducted by Saad et al concluded that compared with patients who received the Lichtenstein patch for ambulatory inguinal hernia repair, patients who underwent the tailored plug-and-patch operation experienced less postoperative pain but consumed similar postoperative analgesic medication. ${ }^{[21]}$ The rate of return to normal activity and work was similar in both the groups, which indicates no superiority for the plug-andpatch operation in overall rehabilitation and societal costs. There were no complications regarding mesh insertion as shrinkage, migration, or infection during early or late postoperative follow up period. In this study, postoperative pain was slightly more common in Lichtenstein $(8 \%)$ as compared to plug and patch (4\%) inguinal hernia repair which concluded that there is statistically not significant difference of pain in both the study group sand all the sedentary worker patients were allowed to resume back to their routine non-strenuous work from three to seven days and strenuous work patients were allowed to resume back to normal activities after 4-6 weeks post-operatively. Studies had shown that there is not much difference of operative time in both techniques of mesh hernioplasties statistically, though plug and patch repair consumes slightly longer time, which is attributed to the time taken to tailor the mesh plug and surgical experience. ${ }^{[21]}$ In this study, there was statistically not significant difference in the operative time of both techniques and most of the cases were completed within a time period of 30-40 minutes. The "return to normal activity" and ,work ${ }^{\text {ee }}$ are the most important value to thecommunity and employer, in a study of Saad A et al showed that there was no statistical difference between Lichtenstein and plug and patch repair. ${ }^{[21]}$ And same results had occurred with Andrew $\mathrm{N}$ et al and Jürgen $\mathrm{Z}$ et al. ${ }^{[38]} \mathrm{In}$ this study, most of the patients were discharged within 48 hours of post-operative period and were allowed to return back to non-strenuous routine activities. The remaining few 
patients were discharged on day 3 and 4 due to presence of minor operative complications like pain and seroma and associated comorbid conditions of patients. Despite a large number of studies in recent years, there is no consensus achieved on the best surgical technique of recurrent hernia repair. ${ }^{[39]}$ Reconstruction by using same tissues which have already failed one or more times previously is unsound. Such tissues are scarred, less vascular and indurated. The high failure rate of recurrent inguinal hernia repair argues convincingly against using these less desirable tissues repairs. ${ }^{[40]}$ Therefore mostsurgeons would agree on the use of a prosthetic mesh repairs in the form of Lichtenstein patch or plug and patch for the surgical treatment of recurrent groin hernia. ${ }^{[41]}$ Tarek IO, Talaat AA, et al. had done a comparative study in the form of Plug and Patch versus Lichtenstein hernioplasty in recurrent inguinal hernias. In the end of their study they found that Lichtenstein and plug and patch repairs are equally effective in the repair of recurrent inguinal hernias. However, plug and patch is superior to mesh patch as patients who had plug and patch had less requirement for postoperative analgesics, shorter hospital stay, earlier return to daily activities and less postoperative complications. ${ }^{[42]}$ While comparing the recurrence in our study groups, in none of patient recurrence was found. Various demographic studies had shown that inguinal hernias are more common statistically in the strenuous workers, who work hard in their daily life leading to protrusion of intra-abdominal contents through the patulous deep inguinal ring and weakened posterior abdominal wall. ${ }^{[21]}$ In our study also prevalence of inguinal hernia was more common in the strenuous patients as compared to sedentary patients. However I would like to add that laparoscopic hernioplasty is also a type oftension-free repair, being popularized and favoured by many patients and surgeons, offering better cosmetic results, better visualization of anatomy, utility in fixing all inguinal hernia defects, less post-operative pain, decreased surgical site infections, lower recurrence, less postoperative complication rates, potential for a faster and comfortable recovery, better patient compliance and rehabilitation, excellent long-term results with minimal risks than the "tension-free" open repairs, when employed by skilled surgeons in advanced laparoscopic techniques. ${ }^{[43]}$ So these days in the era of laparoscopic surgeries, lots of work and studies are being conducted on the various laparoscopic techniques of hernioplasties.

\section{Conclusion}

In conclusion, Both techniques are easy and safe to perform with good results. Due to less dissection and tissue trauma in both the techniques, there is less postoperative pain with better patient compliance and satisfaction. There is no significant difference in the operative time and postoperative complication in both techniques. In both techniques, there is early ambulation, short hospital stay, with no significant time difference in return to normal routine activities.Being tension free repairs, there are negligible or no chances of recurrence in these techniques. So both the techniques, lichtenstein and plug and patch inguinal hernia repair, are equally good in terms of negligible intra-operative, post-operative complications and overall outcome with good patient compliance and satisfaction.

\section{References}

1. Amid P, Shulman AG, Lichtenstein I. The Lichtenstein open tensionfree hernioplasty. In: Arregui ME, Nagan RF. eds. Inguinal hernia. Advances or controversies? Oxford \&N. York: Radcliffe Medical Press; 1994. P. 185-190.

2. McVay CB, Savage LE. Etiology of femoral hernia. Ann Surg. 1961 Dec; 154 (Suppl 6):25-32.

3. Mcvay CB. Inguinal and femoral hernioplasty. Arch Surg. 1948;57:524-30.

4. Zimmerman LM. Surgical management of direct inguinal hernia. SurgGynaeObst. 1938;6:193.

5. Bassini E. Nuovometodo per la cura radical delleerniainguinale. AttiCongrAssoci Med Ital. 1887;2:179-81.

6. Bassini, E. Sulla cura radical delleerniainguinale. Arch SocItalChir. 1887;4:380-88.

7. Bassini, E. Uber de behandlung des leistenbruches. Arch KlinChir. 1890;40:429-76.

8. Mcvay CB. Inguinal hernioplasty: anatomic repair. Arch Surg. 1940;77:213-25.

9. Shearburn EW, Myers RN. Should ice repair for inguinal hernia. Surgery. 1969;66:450-9.

10. Stoppa R, Watlaumont CH, Verhaeghe P, Henry X. Tulle de dacron et cure chirurgicale des hernies de I'aine. Chirurgie. 1983;109:847-54.

11. Lichtenstein IL, Shulman AG, Amid PK, Montllor MM. The tensionfree hernioplasty. Am J Surg. 1989;157:188-93.

12. Rutkow IM, Robbins AW. Tension-free inguinal herniorrhaphy: a preliminary report on the "mesh plug" technique. Surgery. 1993;114:38 .

13. Mckernan JB, Laws HL. Laparoscopic repair of inguinal hernia using a totally extraperitoneal prosthetic approach. SurgEndosc. 1993;7:26-8.

14. Lichtenstein IL, Shore JM. Simplified repair of femoral and recurrent inguinal hernias by a plug technique. Am J Surg. 1974;128:439-40.

15. Gilbert AI. Sutureless repair of inguinal hernia. Am J Surg. 1992;163:331-5.

16. Robbins AW, Rutkow IM. The mesh-plug hernioplasty. SurgClin North Am. 1993;73:501-12.

17. Rutkow IM, Robbins AW. 1669 Mesh plug hernioplasties. Contemp Surg. 1993;43:141-7.

18. Robbins AW, Rutkow IM. Mesh plug repair and groin hernia surgery. SurgClin North Am. 1998;78:1007-23.

19. Kang SK, Burnett CA, Freund E, Sestito J. Hernia: is it a work-related condition? Am J Ind Med. 1999;36(6):638-44.

20. Katz DA. Evaluation and management of inguinal and umbilical hernias. Pediatr Ann. 2001;30(12):729-35.

21. Saad A, Gaber M, Metawe A, Fathy M. J Med Research Ist. 2010;31:24-30

22. Read RC (1996) Hernia. In: Zuidema GD (ed) Shackelford's surgery of the alimentary tract, vol: 5.WB Saunders, Philadelphia, pp 93-226, Stedman's medical dictionary 1982

23. Bendavid R (1989) New techniques in hernia repair. World J Surg 13:522-531

24. Milic DJ, Pejic MA. Tension-free procedures in the treatment of groin hernias. SrpskiArhivZaCelokupnoLekarstvo. 2003;131(1-2):82-91.

25. Usher FC, Hill J, Ochsner J. Hernia repair with surgery. 1959;46:71820.

26. Stoppa RE, Rives JL. The use of dacron in groin hernia repair. SurgClin North Am. 1984;64:269.

27. Gilbert AI, Young J, Graham MF. Combined anterior and posterior inguinal hernia repair. Intermediate recurrence rates with three groups of surgeons. Hernia J Surg. 2004;8:203-7.

28. Lippincott Williams and Wilkins. Repair of Groin Hernia with Synthetic Mesh. Ann Surg. 2002;235(3):322-32.

29. Ahmad S. Conservative management of mesh site infection. J Ayub 
Med Coll Abbottabad. 2007;19(4):75-7.

30. Amid PK, Shulman AG, Lichtenstein IL. Open tension-free repair of inguinal hernias: the Lichtenstein technique. Eur J Surg. 1996;162(6):447-53.

31. Baracs J, Huszár O, Gadácsi M, Horváth OP, Wéber G. Long-term results of open tension-free or tension repair of inguinal herniasretrospective study. MagySeb. 2010;63(5):297-301.

32. Rutkow IM, Robbins AW. Tension-free inguinal herniorrhaphy: a preliminary report on the mesh plug technique. Surgery. 1993;114(1):3-8.

33. Pierides G, Vironen J. A prospective randomized clinical trial comparing the prolene hernia system ${ }^{\circledR}$ and the lichtenstein patch technique for inguinal hernia repair in long term: 2- and 5-year results. Am J Surg. 2011;202(2):188-93.

34. Benizri EI. Open inguinal hernia repair by plug and patch: the value of fibrin sealant fixation. Hernia. 2006;10(5):389-94.

35. Bringman s. Tension-free inguinal hernia repair: tep versus mesh-plug versus lichtenstein. Ann Surg. 2003;237(1):142-7.

36. Millikan KW, Cummings B, Doolas A. The Millikan modified meshplug hernioplasty. Arch Surg. 2003;138(5):525-9.

37. Fei L, Filippone G, Trapani V, Cecchi M, Cuttitta D. New devices for inguinal hernia repair in elderly patients. Acta Biomed. 2005;76(1):33-
6.

38. Jürgen $\mathrm{Z}$, Beatrix $\mathrm{H}$, Frank A. Inguinal hernia repair in the new millennium: plug and patch repair with local anaesthesia. World $\mathbf{J}$ Surg. 2001;25:138-41.

39. Kark AE, Kurzer MN, Belsham PA. Three thousand one hundred seventy five primary inguinal hernia repairs: advantages of ambulatory open mesh repair using local anaesthesia. J Am Col Surg. 1998; 186:447-56.

40. Fasih T, Mahapatra TK, Waddington RT. Early results of inguinal hernia repair by the mesh plug technique- first 200 cases. Ann R CollSurg Engl. 2000;82:396-400.

41. Gianetta E, Cuneo S, Vitale B, Camerini G, Stella M. Anterior tension free repair of recurrent inguinal hernia under local anaesthesia. Ann Surg. 2000;231:132-6.

42. Tarek I, Ayman A. Talaat MD. Comparative study in the form of plug and patch versus lichtensteinhernioplasty in recurrent inguinal hernias. Egyptian J Surgery. 2003;22(1):44-5.

43. Klaristenfeld DD. Minimally invasive tension free inguinal hernia repair. SurgTechnol Int. 2005;14:157-63.

Copyright: (C) the author(s), 2019. It is an open-access article distributed under the terms of the Creative Commons Attribution License (CC BY 4.0), which permits authors to retain ownership of the copyright for their content, and allow anyone to download, reuse, reprint, modify, distribute and/or copy the content as long as the original authors and source are cited.

How to cite this article: Singh DV. Inguinal Hernia Mesh Repairs: Plug and Patch Versus Lichtenstein Mesh Repair Technique: A Teaching Hospital Based Study. Asian J. Med. Res. 2019;8(2):SG15-SG20.

DOI: dx.doi.org/10.21276/ajmr.2019.8.2.SG4

Source of Support: Nil, Conflict of Interest: None declared.

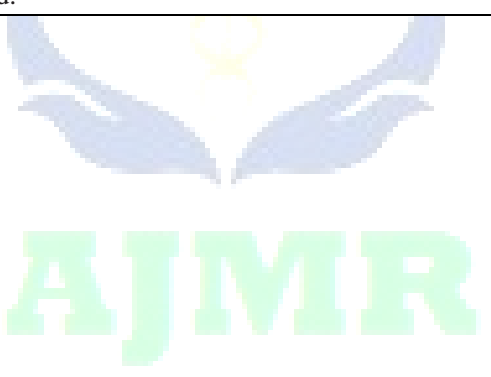

